\title{
Evaluation of Chamomile (Matricaria chamomilla L.) as an Alternative Growth Promoter in Broiler Chicks
}

\author{
M. Akbari, S.S. Ashrafi, M. Bouyeh, J.R. Jaber ${ }^{1}$, A. Seidavi ${ }^{\star}$ \\ and M.R. Ventura ${ }^{1}$ \\ Department of Animal Science \\ Rasht Branch, Islamic Azad University, Rasht, Iran
}

(Received March 26, 2018)

\begin{abstract}
Akbari, M., Ashrafi, S.S., Bouyeh, M., Jaber, J.R., Seidavi, A. and Ventura, M.R. 2020. Evaluation of Chamomile (Matricaria chamomilla L.) as an alternative growth promoter in broiler chicks. Animal Nutrition and Feed Technology, 20: 71-81.

This study was conducted to evaluate Matricaria chamomilla (MC), commonly known as chamomile, as a new growth promoter in broiler chicks and its effects on feed intake, weight gain, feed conversion ratio, carcass characteristics, clinical biochemistry, immunity and digestive bacterial count. A total of 200 day-old male broiler chicks were randomly assigned into five experimental treatments each with four replicates of 10 chicks. The treatments were feeding of commercial diet as a control (CD) and the same supplemented with $M$. chamomilla at 0.3 (MC-0.3), 0.6 (MC-0.6), 0.9 (MC-0.9) and 1.2 (MC-1.2) per cent levels. The addition of MC did not affect feed consumption. Although there were no differences $(\mathrm{P}>0.05)$ among the groups at any of the periods in the feed intake, BW gain and feed conversion ratio. There were, however, differences $(\mathrm{P}<0.05)$ in the European production index $(\mathrm{EPI})$ with the index for chickens fed MC-0.6 being higher as compared with all the other treatments. The immune response to Newcastle disease was higher in MC-0.9 and MC-1.2 groups. The counts of lactobacilli in the intestinal digesta were higher $(\mathrm{P}<0.05)$ in broilers receiving MC-0.6 and MC-0.9 diets than those fed on the CD diet. In respect of plasma clinical biochemistry, differences $(\mathrm{P}<0.05)$ were found in glucose, HDL and uric acid for the different treatments when compared with the control, but the values were within the normal range for poultry. Overall, the present study indicates that the positive effects, if any, of dietary supplementation of chamomile in broilers apparently failed to present a definite trend. Thus, further evaluation is needed in order to establish the proper use, the level of supplementation and the potential beneficial effects that $M$. chamomilla would impart in broilers.
\end{abstract}

Keywords: Broiler chicks, Clinical biochemistry, Growth promoter, Matricaria chamomilla.

\section{INTRODUCTION}

After the prohibition of antibiotics as growth promoters in animal nutrition by the European Union, many research lines have been developed to investigate alternative growth promoting compounds. These new candidates must have, at least, the same

*Corresponding Author: alirezaseidavi@iaurasht.ac.ir

${ }^{1}$ Department of Animal Production, Veterinary Faculty, University of Las Palmas de Gran Canaria, 35412 Arucas, Spain 
beneficial activity of the antibiotics, when used at sub-therapeutic doses as a preventive measure against proliferation of pathogenic bacteria (Feighner and Dashkevicz, 1987).

In this regard Matricaria chamomilla L. (MC), commonly known as chamomile has been suggested to possess health-promoting effects (McKay and Blumberg, 2006). Chamomile belongs to the Asteraceae family and is one of the important medicinal herb native to southern and eastern Europe. It is also grown in Germany, Hungary, France, Russia and Yugoslavia, and introduced to other countries such as North Africa, Asia, North and South America, Australia, and New Zealand (Singh et al., 2011).

The analysis of chamomile flower extract done by Hamady et al. (2017), has showed the presence of several bioactive phytochemical components including pentadecanoic acid, which is a palmitic acid methyl ester reported to have a potential antioxidant and growth promoter activities in broiler chickens (Vijisaral and Arumugam, 2014); $\alpha$-bisabolol (a monocyclic sesquiterpene alcohol), which was found to have an anti-inflammatory, antibacterial and antifungal properties (Kazemi, 2014) and 4,5,9,10dehydro-isolongifolene, a sesquiterpene with potent antioxidant properties (Rangasamy and Namasivayam, 2014). Other compounds that were identified in the analysis done by Hamady et al. (2017) were, 4,7-dihydroxy-coumarin and 7-methoxy-coumarin. Coumarins have a variety of important biological activities such as anti-inflammatory, antioxidant, antiviral and antimicrobial (Al-Majedy et al., 2016). Farnesol was also identified in the chamomile flower extract (Kazemi, 2014). The tested extract was also found to contain the terpene compounds as farnesyl- $\beta$-D-mannofuranoside, phytol and lavandulol that show antimicrobial activity (Gunasekaran et al., 2012). Others activities reported have also been digestive beneficial effects (antispasmodic effect), inhibition of gastric ulcers, or diarrhoea, as well as the modulation of the activity of hepatic cytochrome P450 (Kazemi, 2014). Furthermore, powdered flowers and extracts of chamomile have demonstrated inhibitory effects on the growth of several pathogenic bacteria such as Salmonella spp., Escherichia coli, Enterobacter spp., Enterococcus spp. and others (Al-Kaisse and Khalel, 2011; Dada et al., 2015; Hamady et al., 2017).

Other studies described a wide range of different properties of Matricaria chamomilla in animals (McKay and Blumberg, 2006). There are reports that chamomile flower powder supplementation improved feed intake, weight gain and growth rate of broiler chicks compared with control one (Al-Kaisse and Khalel 2011). However, Dada et al. (2015) reported no beneficial effects in broiler chicks receiving MC. Furthermore, Hamada et al. (2015) reported that chamomile supplementation at different levels reduced final body weight and weight gain in poultry. The aim of this study, therefore, was to evaluate the effects of supplementation of Matricaria chamomilla L. on the growth performance, carcass characteristics, clinical biochemistry, immunity and digestive bacterial count of broiler chicken. 


\section{MATERIALS AND METHODS}

\section{Housing and animals}

The experiment was performed in a commercial poultry farm located in AstanehAshrafiyeh. Prior to the experiment, the facility was cleaned and disinfected, including drinkers and feeders. Continuous controlled temperature $\left(22-25^{\circ} \mathrm{C}\right)$, air humidity $(55$ to $65 \%$ ) and ventilation were implemented according to the instructions for Ross 308 broilers (Aviagen, Newbridge, Scotland, UK 35805).

Chicks were one-day-old male, Ross 308 strain (Aviagen, Newbridge, Scotland, UK 35805), with similar body weights in all groups. The experiment complied with the guidelines for the use of experimental animals by the Ethics Committee of the Islamic Azad University. Environmental conditions and management were identical for all groups during the experiment.

\section{Experimental design, feedstuffs and treatments}

The experimental design was a randomized complete block, with five treatments, four replicates per treatments with ten animals per replicate (a total of 200 male broiler chicks). The experiment lasted $42 \mathrm{~d}$. All chicks were fed a commercial diet according to the producer's recommendation (Table 1). The ingredients of the commercial diet were corn, soybean meal, fish meal, soybean oil, all acquired from the local market (Rasht, Iran). The nutritional contents of the commercial diet in the different growth phases are summarized in Table 1 . The treatments were feeding a commercial diet as a control (CD) and the same supplemented with $M$. chamomilla flower powder at 0.3 (MC-0.3), 0.6 (MC-0.6), 0.9 (MC-0.9) and 1.2 (MC-1.2) per cent levels. The MC flower powder was purchased locally (Rasht, Iran). Feed and water were supplied ad libitum.

\section{Growth performance and feed intake}

Body weight (BW) and feed intake (FI) were recorded weekly for 6 weeks and calculated at d 21 and 42. Feed conversion ratio (FCR) was calculated as the ratio

Table 1. Nutritional composition of the basal diet

\begin{tabular}{lccccc}
\hline Attributes & $\begin{array}{c}\text { Pre-starter } \\
(0-6 \mathrm{~d})\end{array}$ & $\begin{array}{c}\text { Starter } \\
(7-20 \mathrm{~d})\end{array}$ & $\begin{array}{c}\text { Grower } \\
(21-30 \mathrm{~d})\end{array}$ & $\begin{array}{c}\text { Finisher 1 } \\
(30-38 \mathrm{~d})\end{array}$ & $\begin{array}{c}\text { Finisher 2 } \\
(39-42 \mathrm{~d})\end{array}$ \\
\hline Crude protein, \% & 23.5 & 20.5 & 18.6 & 17.0 & 16.2 \\
Crude fiber, \% & NA & 3.5 & 3.2 & 3.6 & 3.0 \\
Crude fat, \% & NA & 4.0 & 3.6 & 3.6 & 3.5 \\
Arg, \% & 1.33 & 1.45 & 1.25 & 1.15 & 0.99 \\
Met+Cys, \% & 1.01 & 0.91 & 0.82 & 0.75 & 0.72 \\
Lys, \% & 1.29 & 1.20 & 1.13 & 0.99 & 0.93 \\
Met, \% & 0.63 & 0.59 & 0.50 & 0.44 & 0.42 \\
Ca, \% & 1.05 & 0.95 & 0.91 & 0.85 & 0.81 \\
Available P, \% & 0.50 & 0.47 & 0.45 & 0.42 & 0.38 \\
ME, kcal/kg & 3000 & 2980 & 3000 & 3020 & 3050 \\
\hline
\end{tabular}


$(\mathrm{g} / \mathrm{g})$ of average feed intake and average BW gain. The European production index (EPI) was calculated according to the formula proposed by Nollet et al. (2008): [(Live weight $(\mathrm{kg}) \times$ livability $(\%)) /(\mathrm{FCR} \times$ age $($ days $)] \times 100$.

\section{Carcass traits}

At d 42, and after $4 \mathrm{~h}$ of fasting, one bird randomly chosen from each replicate $(n=20)$ was slaughtered and used to measure organ weights of the broilers. Carcass components were dissected and separately weighed and recorded.

\section{Clinical biochemistry, immunity response and bacterial count}

At $42 \mathrm{~d}$ of age a 5-ml of blood sample was collected from the ulnaris vein of one randomly chosen bird from each of the replicates (4 birds per treatments), and placed into sodium EDTA. Total plasma cholesterol and triglyceride levels were determined using enzymatic methods according to Schmid and Forstner (1986), while the cholesterol fractions (HDL and LDL) were measured directly with diagnostic kits. Plasma glucose was determined using a glucose oxidase kit according to Trinder (1969) and Barham and Trinder (1972). Plasma uric acid was measured using a uric acid-uricase enzyme kit based on Kato et al. (2000). All the assays were carried out using commercial kits (Teif Azmoon Pars, Co., Tehran, Iran). Birds were vaccinated against different diseases such as infectious bronchitis (IB) at $\mathrm{d} 1$ and $\mathrm{d} 18$, against Newcastle disease at d 10 and 18, against avian influenza at the d 1, and against Gumboro's disease at the d 14 of age. Blood samples were collected from each bird at the d 42 of age to quantify anti-Newcastle Disease antibody titers measured through hemagglutination inhibition test according to Cunningham (1971).

At d 21 of age, one bird per replicate $(n=20)$ was injected intravenously in the breast muscle with $0.3 \mathrm{ml}$ of a sheep red blood cells (SRBC) suspension (1 mL of PBS with $10 \mathrm{~mL}$ of SRBC). Blood samples were collected from each bird at d 42 of age to quantify anti-SRBC antibody titers. Blood samples were collected by puncturing the vena cava into 6-ml vacuutainers with heparin as an anticoagulant (Sigma, Germany) and centrifuged at $10,000 \mathrm{rpm}$ for $15 \mathrm{~min}$. The obtained serum samples were pipetted and stored in 2-ml eppendorf tubes at $20^{\circ} \mathrm{C}$. The total immunoglobulin $\mathrm{M}(\mathrm{IgM})$, and $\mathrm{G}(\mathrm{IgG})$ anti-SRBC antibody titers were determined using a micro-hemagglutination technique (Pourhossein et al., 2015). The antibody data were expressed as the $\log _{10}$ of the reciprocal of the highest dilution giving visible agglutination. Bacterial count in the digesta samples was carried out according to Dibaji et al. (2014) using MRS agar for Lactobacilli, EMB for E. coli and Mac Conkey agar for coliforms. A suspension of bacteria isolated from gastrointestinal digesta from two birds from each replicate was prepared. Lactobacilli bacteria were counted after incubation at $37^{\circ} \mathrm{C}$ in anaerobic conditions for $72 \mathrm{~h}$, and $E$. coli and coliforms counted after incubation at $35^{\circ} \mathrm{C}$ in aerobic conditions for $45 \mathrm{~h}$. Bacteria were counted by colony counter as colony forming units (CFU) and reported as $\log _{10}$ number of bacteria/gram sample. 


\section{Statistical analysis}

Data were subjected to statistical analysis using the General Linear Model procedures (SPSS Statistical package v.20). Differences among means were assessed via Duncan's multiple range tests. Values were considered as statistically significant when $\mathrm{P}<0.05$.

\section{RESULTS}

\section{Growth performance}

The broilers showed good health and normal behavior during the entire experiment. During the starter period (d 1-21), the finisher period (d 22-42) and in the total period $(\mathrm{d} 1-42)$, there were no differences $(\mathrm{P}>0.05)$ in feed intake and BW gain among the dietary groups (Table 2). The FCR (g feed intake/g gain) and EPI values over the $42-\mathrm{d}$ period showed differences $(\mathrm{P}<0.05)$ among the groups, but were similar when period-wise ( $\mathrm{d} 1-21$ or $\mathrm{d} 22-41$ ) comparison was made. The highest FCR was achieved by the MC-0.6 group, which showed significant differences when compared to control, MC-0.3, MC-0.9 and MC-1.2 groups, and EPI was lower in MC-0.6 group as compared with the remaining treatments.

\section{Carcass traits}

There were no significant differences in the weight of the different organs except for the neck and spleen (Table 3). In case of the neck, the MC-0.3 group

Table 2. Effects of graded levels of chamomile supplementation on growth performance of the broilers

\begin{tabular}{lcccccc}
\hline \multirow{2}{*}{ Attribute } & \multicolumn{5}{c}{ Dietary groups $^{\dagger}$} & SEM \\
\cline { 2 - 5 } & CD & MC-0.3 & MC-0.6 & MC-0.9 & MC-1.2 & \\
\hline Body weight $(g)$ & & & & & \\
Starter & 661 & 662 & 665.6 & 666.8 & 664.5 & 16.3 \\
Finisher & 1240.6 & 1242.6 & 1112.2 & 1168.5 & 1290.8 & 123.1 \\
Overall & 1901.7 & 1904.6 & 1777.8 & 1835.3 & 2010.3 & 123.8 \\
Feed intake $(g)$ & & & & & \\
Starter & 1022.2 & 1026.5 & 1026.3 & 1026.5 & 1025.7 & 16.6 \\
Finisher & 3440.2 & 3440.2 & 3258.5 & 3321.2 & 3531.7 & 42.5 \\
Overall & 4462.5 & 4462.5 & 4285 & 4347.5 & 4557.5 & 97.5 \\
Feed conversion ratio $(g$ feed/g BW gain) & & & & & \\
Starter & 1.54 & 1.55 & 1.54 & 1.53 & 1.54 & 0.03 \\
Finisher & 2.78 & 2.77 & 2.93 & 2.85 & 2.74 & 0.10 \\
Overall & $2.34^{\mathrm{a}}$ & $2.34^{\mathrm{a}}$ & $2.41^{\mathrm{b}}$ & $2.37^{\mathrm{ab}}$ & $2.33^{\mathrm{a}}$ & 0.07 \\
EPI & $200.1^{\mathrm{a}}$ & $206.2^{\mathrm{a}}$ & $187.0^{\mathrm{b}}$ & $198.4^{\mathrm{a}}$ & $208.7^{\mathrm{a}}$ & 11.31 \\
\hline
\end{tabular}

The treatments included feeding of commercial diet as a control (CD) and the same supplemented with $M$. chamomilla at 0.3 (MC-0.3), 0.6 (MC-0.6), 0.9 (MC-0.9) and 1.2 (MC-1.2) per cent levels.

European production index.

${ }^{\mathrm{ab}}$ Means with different letters within treatments differ significantly $(\mathrm{P}<0.05)$. 
showed the highest values, while MC-0.9 and MC-1.2 groups showed the lowest $(\mathrm{P}<0.05)$. On the other hand, the weight of spleen was significantly $(\mathrm{P}<0.05)$ higher in $\mathrm{MC}-0.3$ group as compared with the other treatments.

\section{Clinical biochemistry, immunity response and bacterial count}

The data on effects of MC on clinical biochemistry are shown in Table 4. The plasma levels of glucose, HDL and uric acid varied significantly $(\mathrm{P}<0.05)$ among the MC-supplemented groups when compared with the control. The plasma levels of glucose showed a significant reduction in MC-0.9 group and higher plasma levels in MC-0.6

Table 3. Effects of graded levels of chamomile supplementation on the organ weights of the broilers

\begin{tabular}{lcccccc}
\hline \multirow{2}{*}{ Attributes } & \multicolumn{5}{c}{ Dietary groups $^{\dagger}$} & \multirow{2}{*}{ SEM } \\
\cline { 2 - 5 } Organ weight $(g)$ & CD & MC-0.3 & MC-0.6 & MC-0.9 & MC-1.2 & \\
Liver and bile & 54.0 & 61.0 & 48.0 & 54.5 & 54.6 & 4.41 \\
Neck & $56.0^{\mathrm{ab}}$ & $60.5^{\mathrm{a}}$ & $52.0^{\mathrm{ab}}$ & $50.0^{\mathrm{b}}$ & $50.0^{\mathrm{b}}$ & 1.0 \\
Heart & 10.5 & 12.5 & 11.5 & 11.0 & 11.0 & 0.69 \\
Spleen & $2.5^{\mathrm{b}}$ & $4.0^{\mathrm{a}}$ & $2.0^{\mathrm{b}}$ & $2.0^{\mathrm{b}}$ & $2.0^{\mathrm{b}}$ & 1.80 \\
Thymus & 6.5 & 6.0 & 6.0 & 5.0 & 5.0 & 0.74 \\
Bursa & 2.0 & 2.0 & 2.0 & 2.0 & 2.0 & 0.39 \\
Breast & 539.0 & 489.5 & 468.0 & 493.5 & 493.6 & 0.64 \\
Gizzard & 61.0 & 61.5 & 58.5 & 59.5 & 59.4 & 3.24 \\
Wings & 110.0 & 115.5 & 118.5 & 111.0 & 111.3 & 5.93 \\
Thigh & 508.0 & 501.5 & 466.0 & 479.0 & 479.5 & 5.90 \\
Abdominal fat & 22.5 & 29.5 & 23.5 & 23.0 & 23.0 & 2.85 \\
\hline
\end{tabular}

The treatments included feeding of commercial diet as a control (CD) and the same supplemented with $M$. chamomilla at 0.3 (MC-0.3), 0.6 (MC-0.6), 0.9 (MC-0.9) and 1.2 (MC-1.2) per cent levels

${ }^{\mathrm{ab}} \mathrm{Means}$ with different letters within treatments differ significantly $(\mathrm{P}<0.05)$.

Table 4. Effects ofgraded levels of chamomile supplementation on clinical biochemistry of the broilers

\begin{tabular}{lcccccc}
\hline \multirow{2}{*}{ Attributes } & \multicolumn{4}{c}{ Dietary groups $^{\dagger}$} & \multirow{2}{*}{ SEM } \\
\cline { 2 - 5 } & CD & MC-0.3 & MC-0.6 & MC-0.9 & MC-1.2 & \\
\hline Glucose, mg/dL & $174.2^{\mathrm{ab}}$ & $176.4^{\mathrm{ab}}$ & $187.5^{\mathrm{a}}$ & $154.4^{\mathrm{b}}$ & $183.6^{\mathrm{ab}}$ & 11.1 \\
Cholesterol, mg/dL & 135.4 & 211.8 & 141.0 & 139.7 & 216.8 & 7.1 \\
Triglycerides, mg/dL & 67.2 & 86.4 & 64.4 & 30.5 & 61.5 & 13.7 \\
HDL, mg/dL & $78.0^{\mathrm{b}}$ & $81.2^{\mathrm{ab}}$ & $83.0^{\mathrm{ab}}$ & $89.5^{\mathrm{ab}}$ & $95.5^{\mathrm{a}}$ & 7.1 \\
LDL, mg/dL & 74.2 & 106.4 & 69.1 & 44.1 & 109.0 & 13.8 \\
Uric acid, mg/dL & $2.4^{\mathrm{a}}$ & $3.8^{\mathrm{ab}}$ & $4.9^{\mathrm{b}}$ & $3.8^{\mathrm{ab}}$ & $5.0^{\mathrm{b}}$ & 0.79 \\
\hline
\end{tabular}

The treatments includee feeding of commercial diet as a control (CD) and the same supplemented with $M$. chamomilla at 0.3 (MC-0.3), 0.6 (MC-0.6), 0.9 (MC-0.9) and 1.2 (MC-1.2) per cent levels

HDL: high density lipoprotein; LDL: high density lipoprotein.

${ }^{a b}$ Means with different letters within treatments differ significantly $(\mathrm{P}<0.05)$. 
as compared with all other groups. While there were no effects $(\mathrm{P}>0.05)$ of the dietary treatments on the plasma levels of cholesterol, triglyceride and LDL, the HDL values were found to be significantly $(\mathrm{P}<0.05)$ higher in the $\mathrm{MC}-1.2$ group compared to control (CD) group. The serum levels of uric acid was significantly $(\mathrm{P}<0.05)$ higher in $\mathrm{MC}$ 0.6 and MC-1.2 groups compared with the $\mathrm{CD}$ group which showed the lowest value.

The immune response data are shown in Table 5. No significant differences were found in SRBC and the IgG titres when compared to control and with other treatments. But differences $(\mathrm{P}<0.05)$ were found in IgM values where MC-0.3, MC-0.6 and MC0.9 groups showed significant increase. Furthermore, differences $(\mathrm{P}<0.05)$ were found in ND titres where MC-0.3, MC-0.9 and MC-1.2 groups showed the highest levels.

The viable counts of bacteria (lactobacilli, E. coli and coliforms) are summarized in Table 6. While there was no variations $(\mathrm{P}>0.05)$ apparent in the $E$. coli counts in the digesta, a higher $(\mathrm{P}<0.05)$ lactobacilli count was found in the MC-0.6 and MC0.9 groups in comparison to the control CD group. However, the coliform count was significantly $(\mathrm{P}<0.05)$ higher in $\mathrm{MC}-0.6$ group in comparison to all other dietary groups.

Table 5. Effects of graded levels of chamomile supplementation on immune parameters of broilers

\begin{tabular}{lcccccc}
\hline \multirow{2}{*}{ Attributes } & \multicolumn{5}{c}{ Dietary groups $^{\dagger}$} & \multirow{2}{*}{ SEM } \\
\cline { 2 - 5 } & $\mathrm{CD}$ & MC-0.3 & MC-0.6 & MC-0.9 & MC-1.2 & \\
\hline Immune response for total & SRBC, IgG & and $\operatorname{IgM}\left(\log _{10}\right)$ & values \\
SRBC & 3.7 & 4.5 & 4.2 & 3.5 & 4.5 & 0.63 \\
IgG & 1.7 & 1.5 & 2.0 & 1.7 & 2.5 & 0.49 \\
IgM & $2.0^{\mathrm{b}}$ & $3.0^{\mathrm{a}}$ & $2.2^{\mathrm{ab}}$ & $2.7^{\mathrm{ab}}$ & $2.0^{\mathrm{b}}$ & 0.42 \\
Immune response to Newcastle Disease & & & & & \\
HI titre $\left(\log _{10}\right)$ & $2.5^{\mathrm{b}}$ & $3.7^{\mathrm{a}}$ & $2.2^{\mathrm{b}}$ & $4.5^{\mathrm{a}}$ & $4.0^{\mathrm{a}}$ & 0.51 \\
\hline
\end{tabular}

The treatments included feeding of commercial diet as a control (CD) and the same supplemented with $M$. chamomilla at 0.3 (MC-0.3), 0.6 (MC-0.6), 0.9 (MC-0.9) and 1.2 (MC-1.2) per cent levels

${ }^{a b}$ Means with different letters within treatments differ significantly $(\mathrm{P}<0.05)$.

IgG: immunoglobulin G: IgM, immunoglobulin M; SRBC: sheep red blood cells; ND: Newcastle disease.

Table 6. Effects of graded levels of chamomile supplementation onviable counts bacteria in the intestinal digesta of broilers

\begin{tabular}{lcccccc}
\hline \multirow{2}{*}{ Attributes } & \multicolumn{4}{c}{ Dietary groups $^{\dagger}$} & \multirow{2}{*}{ SEM } \\
\cline { 2 - 5 } & CD & MC-0.3 & MC-0.6 & MC-0.9 & MC-1.2 & \\
\hline Lactobacilli, $\log _{10}$ CFU/g & $5.0^{\mathrm{b}}$ & $5.6^{\mathrm{ab}}$ & $6.7^{\mathrm{a}}$ & $6.5^{\mathrm{a}}$ & $6.1^{\mathrm{ab}}$ & 0.27 \\
Coliforms, $\log _{10} \mathrm{CFU} / \mathrm{g}$ & $5.7^{\mathrm{b}}$ & $5.7^{\mathrm{b}}$ & $7.0^{\mathrm{a}}$ & $6.0^{\mathrm{b}}$ & $5.9^{\mathrm{b}}$ & 0.44 \\
E. coli, $\log _{10} \mathrm{CFU} / \mathrm{g}$ & 5.4 & 5.2 & 6.0 & 5.2 & 4.5 & 0.45 \\
\hline
\end{tabular}

The treatments included feeding of commercial diet as a control (CD) and the same supplemented with $M$. chamomilla at 0.3 (MC-0.3), 0.6 (MC-0.6), 0.9 (MC-0.9) and 1.2 (MC-1.2) per cent levels.

${ }^{\mathrm{ab}}$ Means with different letters within treatments differ significantly $(\mathrm{P}<0.05)$. 


\section{DISCUSSION}

In the last decade, many studies have reported a wide range of properties of Matricaria chamomilla in humans and animals (McKay and Blumberg, 2006). Dada et al. (2015) reported no beneficial effects in broiler chicks receiving MC at 0.002 and $0.004 \%$ in feed and 0.0018 and $0.0036 \%$ in water, which could have been due to the facts that these dosages were very low. Furthermore, Hamada et al. (2015) also reported than chamomile supplementation at different levels $(0.25,0.50,0.75$ and $1 \%)$ reduced $(\mathrm{P}<0.05)$ the final $\mathrm{BW}$ and weight gain in broilers. However, the results of this study are in contrast to these reports since chamomile supplementation did not affected feed intake and body weight gain among the dietary groups, although the FCR and EPI values over the 42-d period showed differences $(\mathrm{P}<0.05)$ among the groups. However, these were similar when period-wise (d 1-21 or d 22-41) comparisons was made. Interestingly, the lowest performance in terms of FCR and EPI over the 42 -d period were recorded with chamomile supplementation at $0.6 \%$ level.

Although there were no significant differences in weight gain or feed intake among the groups, the addition of MC flower powder at graded levels in the diet did not affect palatability and acceptability of the feed. In general terms, although our study revealed that the inclusion of MC into the diet at different levels did not cause apparent adverse effects (neither digestive distress nor mortality), the chamomile supplementation seems not be useful in terms of augmenting the growth performance.

For carcass characteristics, significant differences were found in neck and spleen weights only. In contrast, a previous study assessing MC use in broilers reported significant differences in liver and gizzard weights (Al-Kaisse and Khalel, 2011).

Regarding clinical biochemistry, although significant differences were found in glucose plasma levels, HDL and uric acid for the different MC groups when compared with the control, but all these were within the normal ranges in poultry (Campbell, 2004), and hence may not be of any practical relevance.

Recent studies have reported beneficial effects of MC in human patients with type-2 diabetes and poultry in terms of significantly diminished total cholesterol, triglyceride and low-density lipoprotein cholesterol levels (Khan et al., 2014; Rafraf et al., 2015). We found that glucose plasma levels were lower with $0.9 \%$ level of chamomile supplementation and not at the other levels. In contrast, cholesterol, triglyceride and LDL did not show differences $(\mathrm{P}>0.05)$ among groups.

Furthermore, broilers fed on MC- 0.6 and MC-12 had the highest values of uric acid when compared with the control (CD) group. It is, therefore, apparent that the effects of the bioactives present in MC on the metabolism could not be elucidated in a clear manner in the present study. Regarding immune response, significant differences were found in ND titre values indicative of a higher antibody response 
with MC supplementation with the exception of MC-0.6 group. Differences $(\mathrm{P}<0.05)$ were also found in IgM values, showing significant increases in MC-0.3 groups. The immunomodulatory activity in MC could be attributed to initiation of immunostimulating properties of heavy erythrocytes (macrocytes), activization of immunoregulation cells of peripheral blood, and increased sensitivity of effector cells to helper signals (Uteshev et al., 1999).

Recent studies have reported the antibacterial activity of MC (Motealleh et al., 2014; Parlinska-Wojtan and Kus-Liskiewicz, 2016; Hamady et al., 2017)). In our study, the lactobacilli counts showed an increase in almost all MC groups when compared with the control. However, coliform counts were significantly higher in MC-0.6 group. Although the antimicrobial spectrum against enteric and pathogenic bacteria of lactobacilli strains is well known, the present study would indicate that antibacterial property of MC in broilers is without any clear trend.

\section{CONCLUSION}

The present study indicates that the positive effects, if any, of dietary supplementation of chamomile in broilers apparently failed to present a definite trend, further evaluation is needed for establishing the effective level of supplementation and their potential effects that MC would have in broilers.

\section{ACKNOWLEDGMENTS}

The authors wish to thank Rasht Branch, Islamic Azad University, for its financial support (Grant number 17.16.4.6457).

\section{REFERENCES}

Al-Majedy, Y., Al-Duhaidahawi, D., Al-Azawi, K., Al-Amiery, A., Kadhum, A. and Mohamad, A. 2016. Coumarins as potential antioxidant agents complemented with suggested mechanisms and approved by molecular modeling studies. Molecules, 21: 135.

Al-Kaisse, G.A.M and Khalel, E.K. 2011. The potency of chamomile flowers (Matricaria chamomilla L.) as feed supplements (growth promoters) on productive performance and hematological parameters constituents of broiler. International Journal of Poultry Science, 10: 726-729.

Barham, D. and Trinder, P. 1972. An improved color reagent for the determination of blood glucose by the oxidase system analyst. Analyst, 97: 142-145.

Bessey, O.A., Lowry, O.H. and Brock, M.J. 1946. A method for the rapid determination of alkaline phosphatase with five cubic millimeters of serum. Journal of Biological Chemistry, 164: 321-329.

Campbell, T.W. 2004. Clinical chemistry of birds. In: Veterinary Hematology and Clinical Chemistry (Ed. M.A. Thrall). Lippincott, Williams and Wilkins Philadelphia, pp. 479-492.

Cunningham, C.H. 1971. Virologia Practica, 6th ed. Acribia, Zaragoza, p. 260.

Dada, R., Toghyani, M. and Tabeidian, S.A. 2015. The Effect of chamomile flower (Matricaria chamomilla L.) extract and powder as growth promoter on growth performance and digestive organs of broiler chickens. Research Opinions in Animal and Veterinary Sciences, 5: 290-294.

Dibaji, S.M., Seidavi, A.R., Asadpour, L. and Moreira da Silva, F. 2014. Effect of a synbiotic on the intestinal microflora of chickens. Journal of Applied Poultry Research, 23: 1-6. 
Feighner, S.D. and Dashkevicz, M.P. 1987. Sub therapeutic levels of antibiotics in poultry feeds and their effects on weight gain, feed efficiency, and bacterial cholytaurine hydrolase activity. Applied and Environmental Microbiology, 53: 331-336.

Garriga, M., Pascual, M., Monfort, J.M. and Hugas, M. 1998. Selection of lactobacilli for chicken probiotic adjuncts. Journal of Applied Microbiology, 84: 125-132.

Gunasekaran, S., Vijay, T., Sarumathy, K. and Palani, S. 2012. Phytoconstituents evaluation by GCMS and therapeutic efficacy of Grewiaum bellifera on streptozotocin (STZ)-induced diabetic rats. Inter. Journal of Pharmacology and Life Science, 3: 1490-1497.

Hamada, A., Ahmed, K.M., Sadek, A. and Taha, E. 2015. Impact of two herbal seeds supplementation on growth performance and some biochemical blood and tissue parameters of broiler chickens. International Journal of Animal and Veterinary Sciences, 9: 255-260.

Hamady, G.A.A., Abdel-Moneim, M.A., El-Sherbiny, M.A., El-Shinnawy, A.M., Motawe, H.F.A. and El-Chaghaby, G.A. 2017. Chamomile flower extract as natural dietary growth promoter and antioxidant for broiler chickens. Journal of Animal and Plant Sciences, 27: 1479-1487.

Jakubcová, Z., Zeman, L., Mares, P., Mlcek, J., Jurikova T., Dostalová, L., Mrazková, E., Mrkvicová, E., Balla, S. and Sochor, J. 2014a. Effect of chamomile supplements to feeding doses on antimicrobial parameters in poultry. Potravinarstvo Slovak Journal of Food Sciences, 8: 228-232.

Kato, C., Sato, K., Wakabayashi, A. and Eishi, Y. 2000. The effects of allopurinol on immune function in normal BALB/c and SCID mice. International Journal of Immunopharmacology, 22: 547-556.

Khan, S.S., Najam, R., Anser, H., Riaz, B. and Alam, N. 2014. Chamomile tea: herbal hypoglycemic alternative for conventional medicine. Pakistan Journal of Pharmaceutical Sciences, 27: 15091514.

Kazemi, M. 2014. Chemical composition and antimicrobial activity of essential oil of Matricaria chamomilla. Bulletin of Environment, Pharmacology and Life Sciences, 3: 148-153.

McKay, D.L. and Blumberg, J.B. 2006. A review of the bioactivity and potential health benefits of chamomile tea (Matricaria recutita L.). Phytotherapy Research, 20: 519-530.

Motealleh, B., Zahedi, P., Rezaeian, I., Moghimi, M., Abdolghaffari, A.H. and Zarandi, M.A. 2014. Morphology, drug release, antibacterial, cell proliferation, and histology studies of chamomileloaded wound dressing mats based on electro spun nano fibrous poly ([-caprolactone)/polystyrene blends. Journal of Biomedical Materials Research Part B - Applied Biomaterials, 102: 977-987.

Nollet, L., Huyghebaert, G. and Spring, P. 2008. Effect of different levels of dietary organic (Bioplex) trace minerals on live performance of broiler chickens by growth phases. Journal of Applied Poultry Research, 17: 109-115.

Parlinska-Wojtan, M., Kus-Liskiewicz, M., Depciuch, J., Sadik, O. 2016. Green synthesis and antibacterial effects of aqueous colloidal solutions of silver nano particles using camomile terpenoids as a combined reducing and capping agent. Bioprocess and Biosystems Engineering, 39: 1213-1223.

Pourhossein, Z., Qotbi, A.A.A., Seidavi, A.R., Laudadio, V., Centoducati, G. and Tufarelli, V. 2015. Effect of different levels of dietary sweet orange (Citrus sinensis) peel extract on humoral immune system responses in broiler chickens. Animal Science Journal, 86: 105-110.

Rangasamy, K. and Namasivayam, E. 2014. In vitro antioxidant and free radical scavenging activity of isolongifolene. Asian Journal of Biological Science, 7: 13-23.

Singh, O., Khanam, Z., Misra, N., Srivastava, M.K. 2011. Chamomile (Matricaria chamomilla L.): An overview. Pharmacognosy Review, 5: 82-95.

Rafraf, M., Zemestani, M. and Asghari-Jafarabadi, M. 2015. Effectiveness of chamomile tea on glycemic control and serum lipid profile in patients with type 2 diabetes. Journal of Endocrinological Investigation, 38: 163-170. 
Schmid, M. and von Forstner, D, 1986. Laboratory Testing in Veterinary Medicine Diagnosis and Clinical Monitoring, 1st ed. Boehringer Mannheim GmbH, Mannheim, Germany, pp. 253.

Trinder, P. 1969. Determination of blood glucose using an oxidase-peroxidase system with a non-carcinogenic chromogen. Journal of Clinical Pathology, 22: 158-161.

Uteshev, B.S., Laskova, I.L. and Afanasev, V.A. 1999. The immunomodulating activity of the heteropolysaccharides from German chamomile (Matricaria chamomilla) during air and immersion cooling. Eksperimental'naia i Klinicheskaia Farmakologiia, 62: 52-55.

Vijisaral, E.D. and Arumugam, S. 2014. GC-MS analysis of bioactive constituents of Indigofera suffruticosa leave. Journal of Chemical and Pharmaceutical Research, 6: 294-300. 


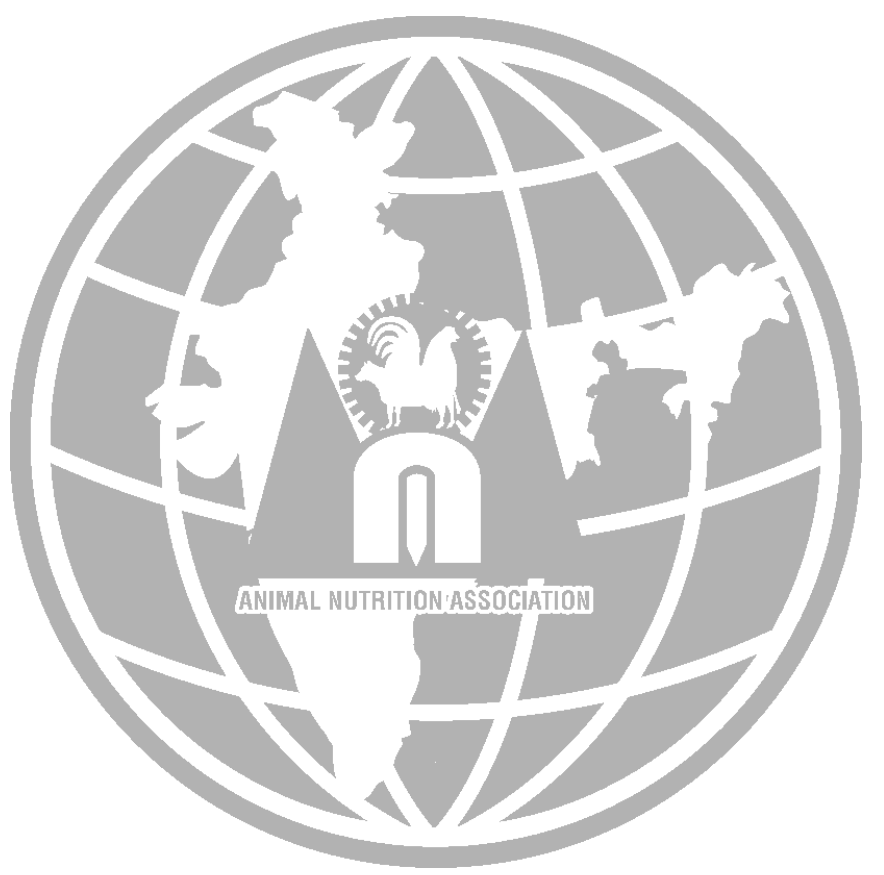

